Article

\title{
Two-Step Downscaling of Trmm 3b43 V7 Precipitation in Contrasting Climatic Regions With Sparse Monitoring: The Case of Ecuador in Tropical South America
}

\author{
Jacinto Ulloa ${ }^{1, *}$, Daniela Ballari ${ }^{1,2,3}$, Lenin Campozano ${ }^{1,3}$ and Esteban Samaniego ${ }^{1,3}$ \\ 1 Departamento de Recursos Hídricos y Ciencias Ambientales, Universidad de Cuenca, Cuenca 010151, \\ Ecuador; dballari@uazuay.edu.ec (D.B.); lenin.campozano@ucuenca.edu.ec (L.C.); \\ esteban.samaniego@ucuenca.edu.ec (E.S.) \\ 2 IERSE, Facultad de Ciencia y Tecnología, Universidad del Azuay, Cuenca 010151, Ecuador \\ 3 Facultad de Ingeniería, Universidad de Cuenca, Cuenca 010151, Ecuador \\ * Correspondence: juv1991@gmail.com; Tel.: +593-995-525-307
}

Received: 02 June 2017; Accepted: 17 July 2017; Published: 22 July 2017

\begin{abstract}
Spatial prediction of precipitation with high resolution is a challenging task in regions with strong climate variability and scarce monitoring. For this purpose, the quasi-continuous supply of information from satellite imagery is commonly used to complement in situ data. However, satellite images of precipitation are available at coarse resolutions, and require adequate methods for spatial downscaling and calibration. The objective of this paper is to introduce and evaluate a 2-step spatial downscaling approach for monthly precipitation applied to TRMM 3B43 (from $0.25^{\circ} \approx 27 \mathrm{~km}$ to 5 $\mathrm{km}$ resolution), resulting in 5 downscaled products for the period 01-2001/12-2011. The methodology was evaluated in 3 contrasting climatic regions of Ecuador. In step 1, bilinear resampling was applied over TRMM, and used as a reference product. The second step introduces further variability, and consists of four alternative gauge-satellite merging methods: (1) regression with in situ stations, (2) regression kriging with in situ stations, (3) regression with in situ stations and auxiliary variables, and (4) regression kriging with in situ stations and auxiliary variables. The first 2 methods only use the resampled TRMM data set as an independent variable. The last 2 methods enrich these models with auxiliary environmental factors, incorporating atmospheric and land variables. The results showed that no product outperforms the others in every region. In general, the methods with residual kriging correction outperformed the regression models. Regression kriging with situ data provided the best representation in the Coast, while regression kriging with in situ and auxiliary data generated the best results in the Andes. In the Amazon, no product outperformed the resampled TRMM images, probably due to the low density of in situ stations. These results are relevant to enhance satellite precipitation, depending on the availability of in situ data, auxiliary satellite variables and the particularities of the climatic regions.
\end{abstract}

Keywords: precipitation; TRMM 3B43 V7; spatial downscaling; gauge-satellite merging; auxiliary satellite variables

\section{Introduction}

Understanding and quantifying the spatiotemporal patterns of precipitation is a subject of great interest in most hydrological and environmental process studies [1]. For this purpose, it is vital to possess accurate precipitation data at appropriate spatiotemporal scales. Precipitation estimates are currently obtained from 2 main sources: rain gauges (in situ data) and satellite imagery (remote sensing data). Obtaining reliable data at high spatial resolutions remains challenging, particularly in 
regions with strong precipitation variability and sparse monitoring [2]. Mountainous environments are particularly inconvenient for the spatial interpolation of precipitation [3]. Significant gradients are often present and are the result of orographic and climatic effects, making it difficult to capture spatial variability [4]. In addition, classical spatial interpolation methods are usually inadequate in areas with an insufficiently dense monitoring network. This is a common issue in areas with complex topography and in developing countries [5].

Considering such difficulties, this study is conducted across the continental area of Ecuador. Despite the fact that the Intertropical Convergence Zone (ITCZ) affects its climate, there are three main climatic regions in Ecuador. The Pacific coastal plains present one rainy season from December to April. The climate in this region is strongly influenced by the Pacific Ocean Sea Surface Temperature, especially from the region Niño 1+2. The main source of interannual variability is El Niño Southern Oscillation (ENSO), producing above/below normal precipitation during El Niño/La Niña periods. At intraannual scales, the South Eastern Pacific Anticyclone inhibits precipitation during October and November. The Andean Mountains display two rainy seasons, February-May and October-November, which is mainly driven by the ITCZ. ENSO influence in the Andes is limited due to high elevations of the cordillera, for instance [6], argues that ENSO influence at an annual scale in Ecuador affects regions below $1200 \mathrm{~m}$ a.s.l. In the Amazon rainforest, a third peak is added to the bimodal signal during July; thus, rainfall in this region is consistently present throughout the year. The effect of ENSO in the Amazon is opposite to the coastal plains; however, during very strong El Niño periods, above normal precipitation is expected.

Individually, both ground measurements and satellite imagery present significant drawbacks for the accurate estimation of precipitation. The commonly used tipping bucket gauges are challenged by random errors induced by loss of water during high intensities, evaporation, and wind [7]. Additionally, point estimations do not accurately reflect spatial variability because they are not a true representation of the areal precipitation [2]. Thus, in situ data is considered weak when applied to hydrological models [8]. Studies have shown that model outcomes are influenced by spatial resolution, and using rasterized continuous precipitation outperforms the use of in situ data [9]. Because classical interpolation techniques fail in sparsely monitored regions, spatially continuous data from satellite images provide an important alternative.

The Tropical Rainfall Measuring Mission (TRMM) 3B43 product provides continuous temporal and spatial coverage at a resolution of $0.25^{\circ}(\approx 27 \mathrm{~km}$ at the Equator). However, precipitation is measured indirectly, resulting in errors related to lack of detection, false detection and bias. Thus, validation with ground measurements is necessary [10]. As mentioned in [2], TRMM images have shown different accuracy, depending on the region of interest and the validation methodology. It has also been reported that the topography of the area imposes additional uncertainty in TRMM estimates, especially when orographic effects play a significant role in rainfall patterns [11]. [12,13] quantified inconsistencies between TRMM and in situ measurements in Thailand and Africa, respectively. In [14], TRMM was evaluated in the Pacific-Andean region of Ecuador and Peru. It was shown that the satellite data reflects the main seasonal features, and that the catchments of southern Ecuador and northern Peru are quantitatively well estimated. In [15], the TRMM 3B43 V7 product was validated across the 3 main geographic regions of Ecuador using 14 stations. It was found that seasonality is well estimated by TRMM in the Coast and the Amazon, especially for light precipitation rates, and that the overall TRMM performance decreases in the Andes. Despite these validation studies, monthly TRMM precipitation still needs to be evaluated in the entire continental area of Ecuador with a higher number of in situ stations. In addition, satellite-merging methods at a regional scale are required to deal with the issues described above, and downscaling procedures over TRMM products are necessary to obtain high resolution precipitation images.

A useful complement of precipitation estimates is the use of auxiliary or secondary variables, which are usually available at finer resolutions than precipitation products. Several works explore the relationship between rainfall and potential auxiliary variables. Precipitation has been shown to have a 
direct relationship with elevation, mainly due to orographic effects [16,17]. In [18], high correlation was found between the Normalized Vegetation Index (NDVI) and precipitation at a global scale. In a zone with a strong precipitation gradient, [19] revealed that the correlation between NDVI and precipitation has spatiotemporal variability. Furthermore, several works study the dynamics of atmospheric variables and their relationship with precipitation. In [20], Advanced Very High Resolution Radiometer (NOAA-AVHRR) images were used to analyze cloud top height, liquid water path and cloud frequency in Ecuador. The study revealed a strong correlation between cloudiness and rainy seasons. The same variables from the NOAA data set, as well as reanalysis data, were used in [21] to study the spatiotemporal patterns of rainfall in the Paute river basin of the Andes in Ecuador. Models based on the auxiliary variables and principal component analysis were applied to reveal the spatial extensions of different precipitation regimes.

The relationship between auxiliary variables and rainfall has been exploited for the continuous mapping of precipitation through geographic information system (GIS) techniques. For instance, a geostatistical method with the inclusion of topographic variables was applied in [22]. In [23], a regression model including a cloudiness factor, solar radiation, and topographic features was used.

Additionally, auxiliary variables have been applied to downscale satellite-born products, particulary TRMM, from $0.25^{\circ}$ to $1 \mathrm{~km}$. In [9], NDVI was used for downscaling TRMM in the Iberian Peninsula at an annual time scale by defining the relationship with precipitation at an optimum spatial scale. In [24], the method was improved in the Qaidam Basin of China by including a Digital Elevation Model (DEM) in multiple regression models at different spatial resolutions. NDVI and DEM were used in North China in [25], where geographically weighted regressions (GWR) outperformed multiple linear regressions. The same independent variables were applied in [26] for annual precipitation in mainland China, where the Random Forest regression furnished promising results for large areas, outperforming the multiple linear regression and exponential models. This machine learning approach was further developed in $[27,28]$ for the Tibetan Plateau. The former applied post-calibration using ground measurements, while the latter incorporated land surface temperature. These studies provide fruitful insights for downscaling procedures using auxiliary variables. Nevertheless, most works have approached TRMM downscaling at an annual time scale and have generally used elevation and vegetation indices, without exploring potential atmospheric auxiliary variables. In addition, TRMM 3B43 V7 has not been downscaled across the study area covered in this work.

Complementary calibration of TRMM products with in situ data (gauge-satellite merging) is often applied to improve precipitation maps. In [2], regression analysis and geographical differential analysis were carried out. Regression analysis was also performed in [29]. In [30], TRMM bias was corrected over the mountainous regions of Peru. Geostatistical techniques were analyzed in [31] to map annual rainfall in Colombia, where kriging with external drift produced the best results. Within the study area covered in this work, [1] used TRMM images, NDVI and DEM to map precipitation at a resolution of $1 \mathrm{~km}$ and a weekly time scale for the Tungurahua province in Ecuador. The results revealed that the performance of the method is related to the density of the station network. Furthermore, NDVI was used as an auxiliary variable in [32], where a very large area of almost 4 countries (Colombia, Ecuador, Brazil and Peru) was covered, where TRMM was merged with 273 in situ stations. However, climatological maps were generated, making it still necessary to treat time series at finer temporal scales over the study area.

In the aforementioned works, fruitful results have been obtained for validation, calibration, or downscaling of TRMM products. However, it is still necessary to evaluate the performance of monthly precipitation maps across extensive climatic regions with sparse in situ monitoring and explore potential enhancements in terms of both spatial resolution and calibration. Thus, the objective of this paper is to explore a 2-step downscaling approach of monthly TRMM in the continental area of Ecuador. Rather than relying on standard downscaling techniques, in this approach, the first step provides resolution enhancement of the TRMM 3B43 V7 data set by a simple method, namely bilinear 
resampling. This step generates a smooth interpolated surface and adds no additional information to TRMM 3B43 V7. Then, using the resampled TRMM images as input variables, the second step introduces further spatial variation by means of gauge-satellite merging techniques and the inclusion of fine-scale auxiliary atmospheric and land variables. The final monthly estimations are obtained at a $5 \mathrm{~km}$ resolution during the period 2001-2011. The proposed methodology was evaluated specifically on each climatological region of Ecuador, which offers a privileged natural laboratory due to the strong climate variability across relatively short distances.

\section{Study Area and Data}

\subsection{Study Area}

This research covers the continental territory of Ecuador (South America, 250,000 km²), which consists of 3 main geographic regions: the coastal plains (Coast), the Andes (along with the interandean valleys) and the Amazon rainforest. The climate of Ecuador is influenced by a variety of factors. From east to west, a strong precipitation gradient crosses the three geographic regions. This is mainly the result of orographic effects induced by the Andean Cordillera, which runs from north to south and acts as a climate barrier [33]. Additionally, several climatic effects are present, which vary from region to region. As a result, precipitation has a strong spatiotemporal variability. As detailed in [21], in the coastal plains, west of the cordillera, precipitation is influenced by the region Nino $1+2$ and by the Intertropical Convergence Zone (ITCZ), which result in a rainy season from December to April. In the interandean valleys, a bimodal regime is present, with a dry period from June to September. In the Amazon, east of the Andes, the ITCZ and moist air from the Amazon basin modulate a year-round rainfall pattern, although a bimodal regime is also present, with two rainy periods during March-April and October-November.

Despite the complex climate, Ecuador is a sparsely monitored region, particularly in the Amazon rainforest. In order to account for the different climate zones and the difference in network densities in each zone, the validation results were interpreted independently in the 3 climatic regions, where a $1000 \mathrm{~m}$ a.s.l. contour line was used for delimitation.

\subsection{In Situ Data and Satellite Imagery}

A monthly data set of rainfall stations from the Ecuadorian National Institute of Meteorology and Hydrology (INAMHI) was used, covering a time period from January 2001 to December 2011. To avoid discarding valuable stations, a maximum of $12 \%$ of monthly gaps was considered per station, which results in a selection of 117 stations for the study. Figure 1 shows a digital elevation map of the delimited study area and the distribution of monitoring stations, where the sparseness of the network is evident.

The satellite-based data used in this study comes from three sources: the Tropical Rainfall Measuring Mission (TRMM), the Moderate Resolution Imaging Spectroradiometer (MODIS) and the NOAA/OAR/ESRL Physical Sciences Division (PSD). For the images whose native resolution is originally in equal-degree grids, resampling to equal-area grids at a resolution of $5 \mathrm{~km}$ was applied to match the desired output resolution.

TRMM, which is a joint space mission between NASA and the Japan Aerospace Exploration Agency (JAXA), provides precipitation images at finer spatial resolutions than other satellite-based rainfall estimates. Among its products, the TRMM 3B43 V7 collection is used in this study, which consists of $0.25^{\circ}(\approx 27 \mathrm{~km}$ at the Equator) resolution monthly images for the region between $50^{\circ} \mathrm{S}$ and $50^{\circ} \mathrm{N}$. This data is produced by the TRMM Multi-satellite Precipitation Analysis (TMPA), combining precipitation estimates from various sensors with rain gauge measurements to correct bias. For details on this data, the reader is referred to [34]. In this study, the original TRMM images are resampled to $5 \mathrm{~km}$ using bilinear resampling. The resulting data set is used directly as the first mapping alternative, and as an independent variable in the other methods. 

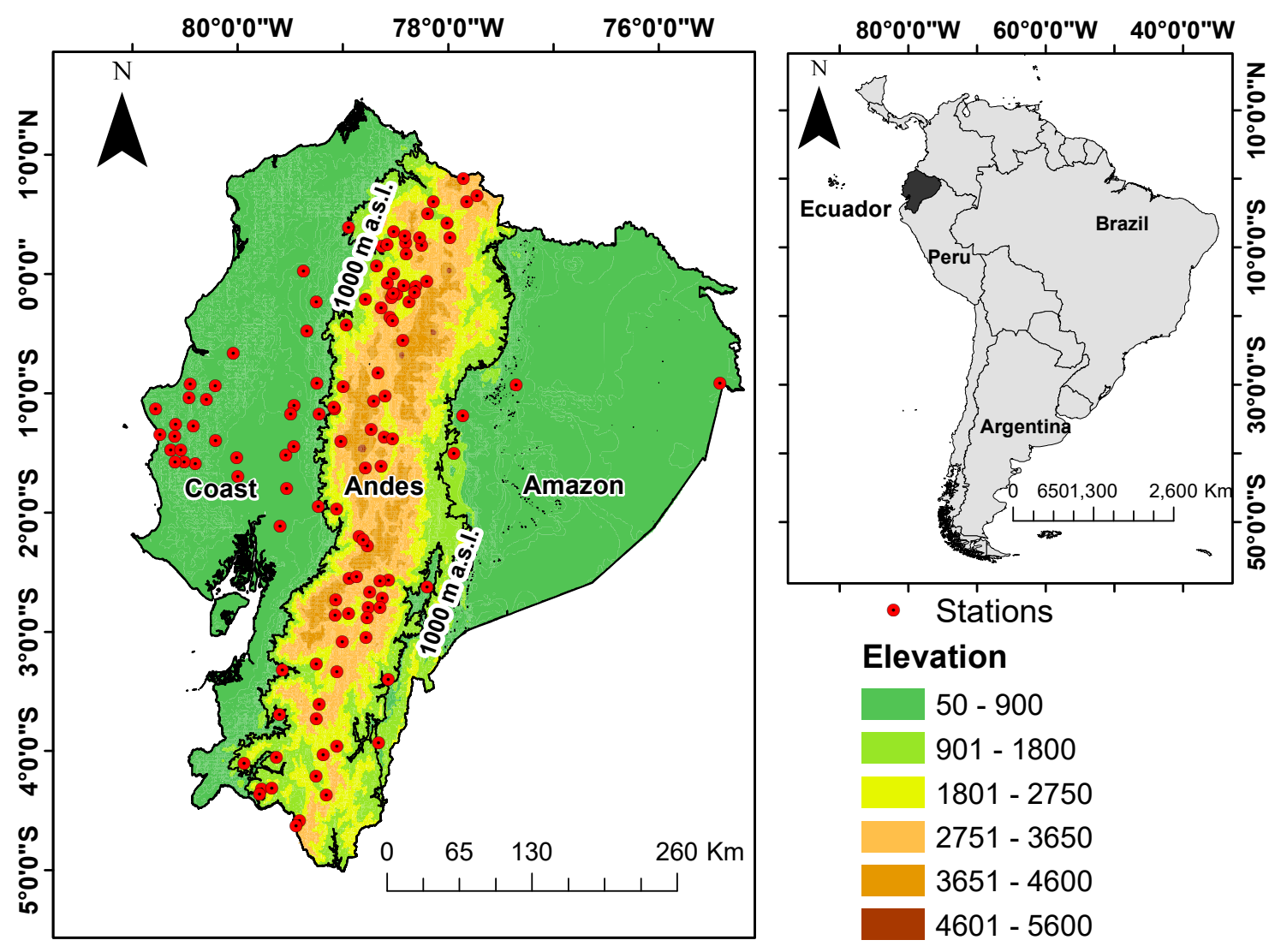

Figure 1. Digital Elevation Map (DEM) of the delimited study area and rain gauge stations network.

The MODIS sensor, aboard the TERRA and AQUA satellites, covers the entire Earth's surface every 1 to 2 days. Data is acquired in 36 spectral bands, providing atmospheric, land, and ocean images, and can be obtained in Level-2 (swath) and Level-3 (global gridded statistic) products. These are available in Hierarchical Data Format (HDF) files containing several data sets. From the MODIS TERRA Collection 006, the following products are used:

- The Level-2 MOD06 from the atmosphere products, which contains several cloud properties at $1 \mathrm{~km}$ and $5 \mathrm{~km}$ resolutions. For details on MODIS cloud products, the reader is referred to [35]. Swath products cover the study area at different times throughout the day, thus, monthly average images are generated at $5 \mathrm{~km}$ resolution for cloud top temperature and cloud fraction (hereafter CTT and $C F$, respectively).

- The Level-3 MOD13C2 from the land products, which provides global monthly NDVI values at $0.05^{\circ}(\approx 5.6 \mathrm{~km})$ resolution in a Climate Modeling Grid $(\mathrm{CMG})$. For details on this product, see [36]. $5 \mathrm{~km}$ monthly NDVI images are obtained via bilinear resampling for the study area (hereafter simply referred to as NDVI).

The CPC Soil Moisture collection provided by the NOAA/OAR/ESRL PSD contains monthly averaged soil moisture images, which consist of global model-calculated water height equivalents at a spatial resolution of $0.5^{\circ}(\approx 55 \mathrm{~km})$. Bilinear resampling is applied to obtain monthly soil moisture images for Ecuador at a $5 \mathrm{~km}$ resolution (hereafter $S M$ ). Ideally, soil moisture data with a finer scale should be considered; however, no other collection is available to the knowledge of the authors for the region and time period of study. Additionally, bilinear resampling of this data and its incorporation into the models improves the cross-validated results. 


\section{Two-Step Downscaling Approach}

The outcome of this work is a data set of $5 \mathrm{~km}$ monthly precipitation maps for an 11 year period between 2001 and 2011 due to data availability. Five products at a $5 \mathrm{~km}$ spatial resolution result from the 2-step downscaling approach:

\section{Step 1}

- $\quad P_{T 5}:$ resampled TRMM images (reference product). Due to its simplicity, bilinear interpolation is applied.

\section{Step 2}

- $\quad P_{R T}$ : a regression model with in situ data using $P_{T 5}$ as the independent variable.

- $\quad P_{R K T}$ : a regression kriging model with in situ data and $P_{T 5}$ as the independent variable.

- $\quad P_{R T C}:$ a multivariate regression model with in situ data using $P_{T 5}$ and auxiliary variables.

- $\quad P_{R K T C}$ : a multivariate regression kriging model using $P_{T 5}$ and auxiliary variables.

The $P_{T 5}$ product resulting from step 1 is used as a benchmark to explore potential enhancements of the 4 methods from step 2, which merge in situ data with the resampled TRMM images. For the multivariate models, atmospheric and land auxiliary variables are selected for each month based on correlation and multicollinearity. Given that step 1 only interpolates the rainfall surface, the purpose of step 2 is to introduce spatial variation that is not accounted for by TRMM 3B43. Note that, in step 2, although $P_{T 5}$ is an independent variable, it is not considered an auxiliary variable for nomenclature purposes. The term auxiliary variables only refers to the atmospheric and land variables used in the multivariate methods.

The processing of satellite images, which includes reformatting, subsetting, reprojecting and resampling, was performed using both the HDF-EOS To GeoTIFF Conversion Tool (HEG) and R programming language. The implementation of the different methods and the corresponding analyses were entirely conducted in $\mathrm{R}$ programming language. In Figure 2, the work flow of the overall procedure is presented.

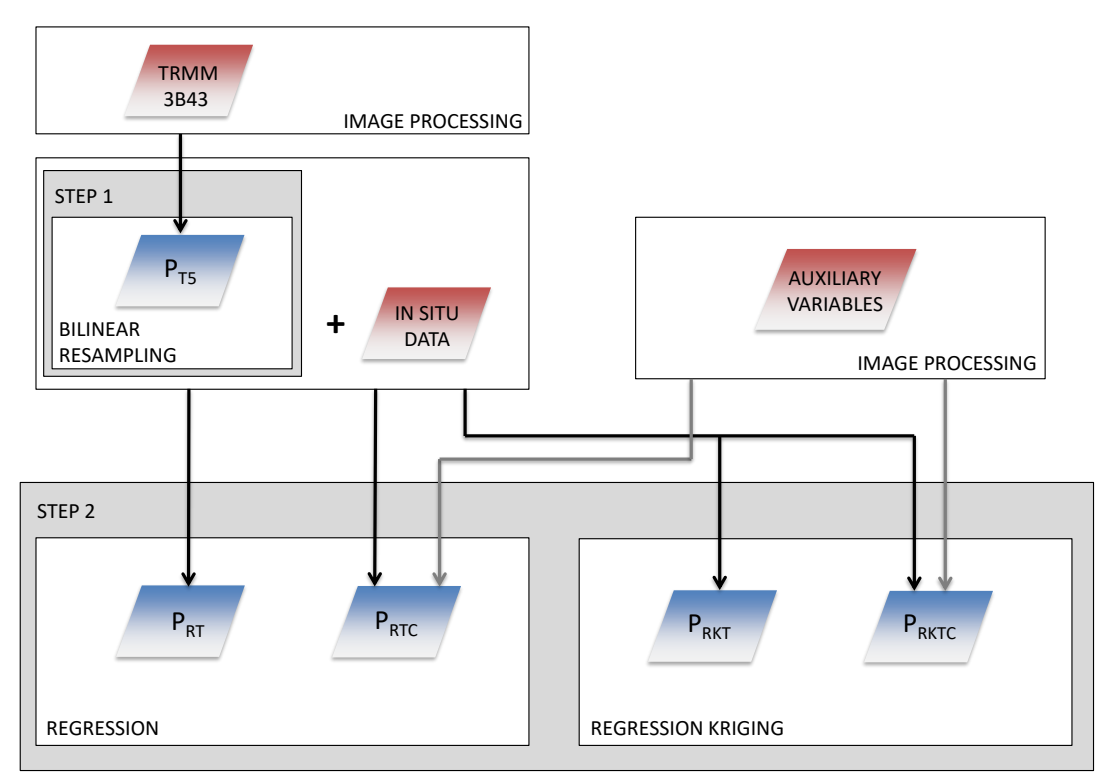

Figure 2. Work flow of the overall downscaling procedure and the 5 resulting products. 


\subsection{Step 1: Image Resampling}

In order to generate the $5 \mathrm{~km}$ output resolution, four-point bilinear resampling is applied to TRMM 3B43 (originally $0.25^{\circ}$ ) as a first step, from where $P_{T 5}$ stems out and is used as a reference product. This interpolation technique is the simplest method that provides a smooth interpolated precipitation surface, which is calibrated in step 2 with in situ data and auxiliary variables.

In addition to constituting step 1 of the downscaling procedure, bilinear resampling is also applied to 2 auxiliary variables: NDVI and soil moisture (originally $0.05^{\circ}$ and $0.5^{\circ}$, respectively).

\subsection{Step 2: Gauge-Satellite Merging}

\subsubsection{Underlying Model Assumptions}

For step 2, precipitation $P$ is assumed as the response of a function of $k$ independent variables $v_{j}$ (which, in this context, include $P_{T 5}$ and the auxiliary variables). Given that $P \in[0, \infty)$, and following [21], an exponential model is adopted. Assuming additive decomposition and neglecting interaction effects,

$$
\ln (P)=f\left(v_{1}, v_{2}, \ldots, v_{k}\right)=\sum_{j=1}^{k} f_{j}\left(v_{j}\right)+\epsilon,
$$

where $\epsilon$ is a random error term. The simplest function that can be assumed is a linear model of the form $\ln (P)=\alpha_{0}+\sum_{j=1}^{k} \alpha_{j} v_{j}+\epsilon$, where $\alpha_{j}$ are constant coefficients. However, preliminary results showed that a model of this form results in significant overestimation of certain observations, generating large residuals. Therefore, the following model is adopted:

$$
\ln (P)=\alpha_{0}+\sum_{j=1}^{k} \alpha_{j} \ln \left(v_{j}\right)+\epsilon,
$$

which can also be expressed as

$$
P=e^{\alpha_{0}} e^{\epsilon} \prod_{j=1}^{k} v_{j}^{\alpha_{j}}
$$

\subsubsection{Regressions}

The parameters of Equation (1) are obtained by linear regression analysis, resulting in an intrinsically-linear non-linear model (i.e., linear in the parameters and non-linear in the variables). Individual regressions are performed for each month using $n$ observation points (in this case, 117 stations). Further assumptions must be made, namely, that the secondary variables are independent and that the errors are normally and independently distributed with mean 0 and constant variance. Considering, for the month $m, k$ independent variables and $n$ observations $\left(v_{m i j}, P_{m i}\right)$, with $(i, j) \in \mathbb{Z}$, $(1 \leq i \leq n, 1 \leq j \leq k)$, Equation (1) relates the observations as

$$
\ln \left(P_{m i}\right)=\alpha_{m 0}+\sum_{j=1}^{k} \alpha_{m j} \ln \left(v_{m i j}\right)+\epsilon_{m i} .
$$

In matrix form, $\hat{\alpha}_{m}$ is an estimator of the real coefficient vector $\alpha_{m}$ and is found by applying least squares:

$$
\hat{\boldsymbol{\alpha}}_{m}=\left(\boldsymbol{V}_{m}{ }^{\prime} V_{m}\right)^{-1} V_{m}{ }^{\prime} \boldsymbol{P}_{m}
$$

where $V_{m}$ is the matrix of the natural logarithm of the $n$ observations of $k$ independent variables and $\boldsymbol{P}_{m}$ is the vector of the natural logarithm of the $n$ measured precipitation values. The precipitation estimates for the regression models $\hat{P}_{m}^{R}$ at any location $(x, y)$ are then given by

$$
\hat{P}_{m}^{R}(x, y)=\exp \left(\hat{\alpha}_{m 0}+\sum_{j=1}^{k} \hat{\alpha}_{m j}\left(\ln \left(v_{m j}(x, y)\right)\right) .\right.
$$


The model given by Equation (4) is applied in step 2 in 2 methods: using $P_{T 5}$ as the only predictor $\left(P_{R T}\right)$ and using $P_{T 5}$ and a selection of auxiliary variables from CTT, CF, NDVI and SM as multiple predictors $\left(P_{R T C}\right)$. Topographical effects are not considered because no correlation was found in preliminary analyses with precipitation, which is probably due to adopted time scale and the extent of the study area, as well as the contrasting climate in the 3 regions. In addition, latitude and longitude are not considered because they are correlated with the adopted auxiliary variables.

\subsubsection{Regression Kriging}

The regression kriging models are divided into a deterministic and a stochastic component, given by the regression model and the error term, respectively. The regression models detailed in the previous section are applied to estimate the first two terms of the underlying model in Equation (1), which correspond to the deterministic part. By applying regression kriging, the random error term is also taken into account (for details on this method, see [37]). The residuals are interpolated using ordinary kriging, where the error value $\epsilon_{m}$ at an unsampled location $(x, y)$ is given by

$$
\epsilon_{m}(x, y)=\sum_{i=1}^{n} \lambda_{m i}(x, y) \epsilon_{m i}
$$

where $\lambda_{m i}(x, y)$ are the kriging coefficients at the unsampled location and $\epsilon_{m i}=P_{m i}-\hat{P}_{m i}^{R}$ are the residuals at the measured locations. Joining the deterministic part given by Equation (4) and the stochastic component given by Equation (5), the precipitation estimates for the regression kriging model $\hat{P}_{m}^{R K}$ at any location $(x, y)$ are

$$
\begin{aligned}
\hat{P}_{m}^{R K}(x, y) & =\exp \left(\hat{\alpha}_{m 0}+\sum_{j=1}^{k} \hat{\alpha}_{m j} \ln \left(v_{m j}(x, y)\right)+\sum_{i=1}^{n} \lambda_{m i}(x, y) \epsilon_{m i}\right) \\
& =\hat{P}_{m}^{R}(x, y)+\epsilon_{m}(x, y)
\end{aligned}
$$

This model is also applied in step 2 using $P_{T 5}$ as the only predictor $\left(P_{R K T}\right)$ and for the multivariate case with $P_{T 5}$ and the selection of auxiliary as multiple predictors $\left(P_{R K T C}\right)$.

\subsubsection{Auxiliary Variable Selection}

The predictors $v_{j}$ used in the previous section consist of $P_{T 5}$ and a selection of auxiliary variables from $C T T, C F, N D V I$ and $S M$. Two selection criteria are applied for each month. First, the auxiliary variables that meet a threshold correlation coefficient with the observed precipitation values are pre-selected. In case two or more variables meet the first criterion, variable redundancy is avoided by removing variables that result in multicollinearity. For this purpose, the variance inflation factor $(V I F)$ is calculated for each variable as

$$
V I F_{j}=\frac{1}{1-R_{j}^{2}}
$$

where $R_{j}^{2}$ is the multiple $R^{2}$ for the regression of predictor $j$ on the other auxiliary variables. In this work, by trial and error, threshold values are set to 0.3 and 5 for the correlation coefficient and $V I F$, respectively.

\subsection{Validation}

In order to cross-validate the results, the methods from step 2 were developed in a leave-one-out scheme. The maps resulting from $P_{T 5}$, which purely contain TRMM information, are used as a reference to explore the potential enhancements of step 2. Statistics are computed comparing the time series of the 5 downscaled products with the in situ measured time series in each station. $R^{2}$ values are considered to test how each model captures seasonality. Also, the root-mean-square error (RMSE) and percent bias (PBIAS) are used for validation, which are given for each station by 


$$
\text { PBIAS }_{i}=100 \frac{\sum_{m=1}^{N}\left(\hat{P}_{m i}-P_{m i}\right)}{\sum_{m=1}^{N} P_{m i}}, \quad R M S E_{i}=\sqrt{\frac{1}{N} \sum_{m=1}^{N}\left(\hat{P}_{m i}-P_{m i}\right)^{2}},
$$

where $\hat{P}_{m i}$ is the precipitation estimate and $P_{m i}$ is the measured value for the $m t h$ month and the ith station, and $N$ is the total number of months. The criteria for enhancements are decreasing RMSE, obtaining positive and lower PBIAS, and increasing $R^{2}$ when compared to the reference map $P_{T 5}$. The reason to pursue a positive PBIAS is based on a conservative approach in terms of cost-risk. An overestimation of precipitation (i.e., false-positive flooding) would be less harmful to population and production than an underestimation (i.e., false-negative flooding). Because of their robustness, median and interquartile range (IQR) values of the statistics are chosen as measures of central tendency and dispersion, respectively.

\section{Results}

\subsection{Correlation With Auxiliary Variables}

As described in the previous section, in order to ensure the inclusion of pertinent independent variables in the multivariate methods, correlation with the observed data is verified for each auxiliary variable. Given the strong spatiotemporal variability of precipitation in the study area, variables were selected independently for each month. In Figure 3, the correlation values for each auxiliary variable and in situ precipitation are summarized, where the temporal variability of each relationship can be observed.

CTT

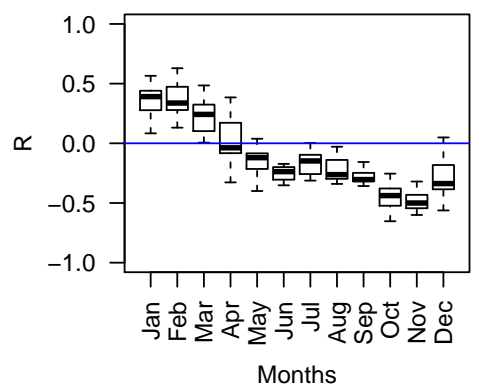

NDVI

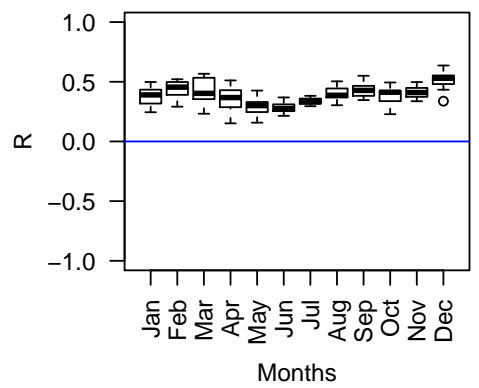

$C F$

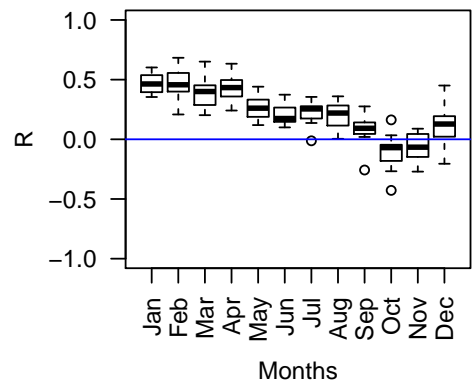

$S M$

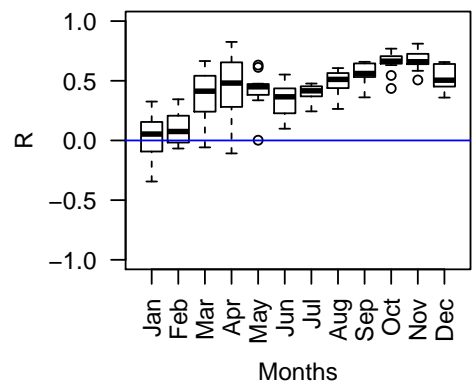

Figure 3. Correlation summary between each auxiliary variable and the observed precipitation data for the time period of study. 


\subsection{Spatiotemporal Precipitation Variability}

The monthly maps resulting from the different methods present spatiotemporal variations. An example of this is displayed in Figures 4 and 5, corresponding to a rainy month (April 2011) and a dry month (August 2011), respectively (note that different color scales are used for both months due to the high difference in precipitation values). The 5 downscaled products are shown for both months, as well as the original TRMM 3B43 V7 images (hereafter $P_{T 0.25^{\circ}}$ ). It can be observed that the overall spatial variability of $P_{T 0.25^{\circ}}$ is captured by the downscaled products. In the downscaled maps, the rainy season in the 3 regions is reflected when comparing the maps from April with August; particularly, the unimodal regime of the Coast is clearly displayed. However, among the products, different patterns can be observed.

A considerably homogeneous spatial distribution of precipitation is shown for both months in $P_{T 5}, P_{R T}$ and, to a lesser degree, in $P_{R K T}$. This is an expected result, given that bilinear interpolation was used to downscale the original TRMM images. It can be observed that more spatial variability was captured by $P_{R T C}$ and $P_{R K T C}$ due to the inclusion of auxiliary variables, which, with the followed validation, can be considered an important enhancement. For instance, the Andes presents a more heterogeneous spatial distribution, which is a well-known characteristic of mountainous regions. The accuracy of these spatial predictions is presented in the following section.

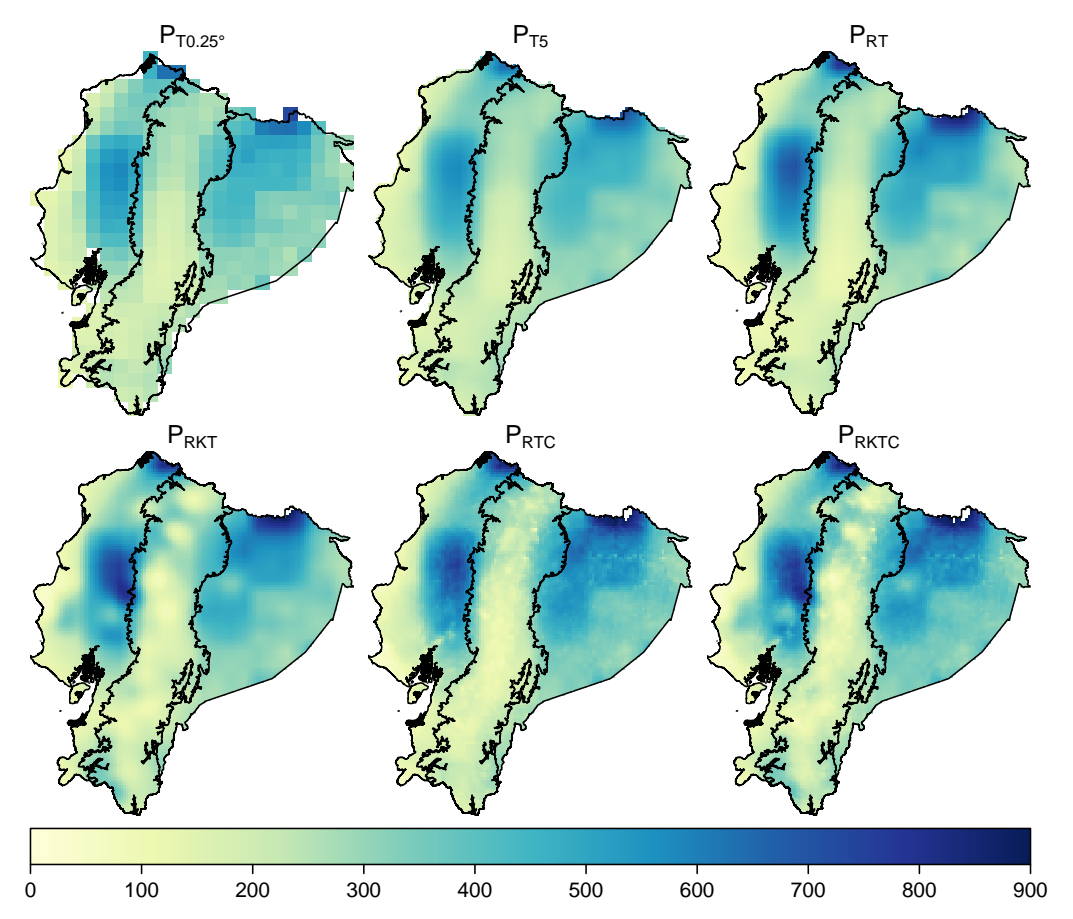

Figure 4. Monthly precipitation [mm] of April 2011 for the five products and the original TRMM data. 


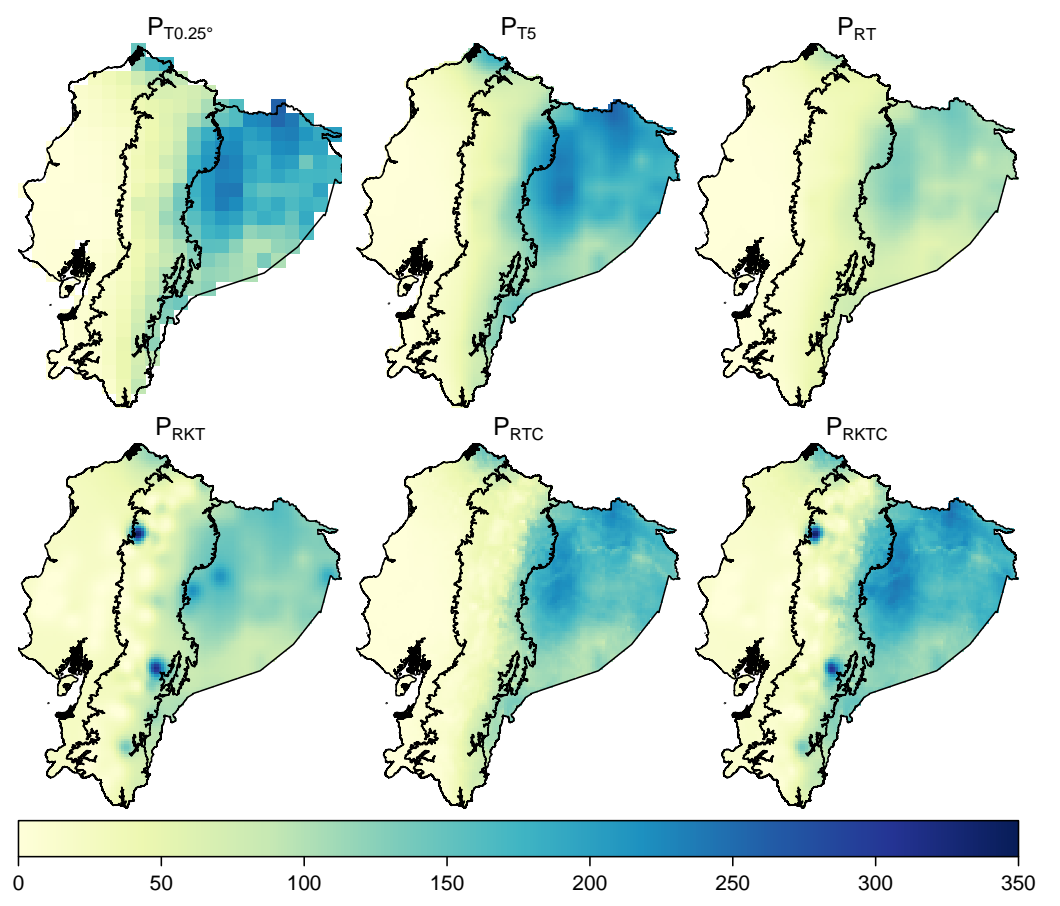

Figure 5. Monthly precipitation [mm] August 2011 for the five products and the original TRMM data.

Both monthly maps of $P_{T 5}$ indicate that in the Amazon region, rainfall is consistent throughout the year. However, in $P_{R T}$ and $P_{R K T}$, August rainfall was significantly decreased across the region. This effect was considerably reduced in $P_{R T C}$ and $P_{R K T C}$, which indicates that auxiliary variables may help to reduce the negative effect that the lack of in situ stations plays in the methods from step 2. Unfortunately, the lack of monitoring also implies uncertainty in this result.

In April, compared to $P_{T 5}$, the 2-step products exhibit distinctive zones with higher precipitation in the Amazon and in the Coast, especially when regression kriging was applied. Given that, in the following section, it is shown that $P_{T 5}$ underestimates precipitation in the Coast, these results suggest that regression kriging tends to adjust TRMM estimates in rainy months. On the other hand, the August maps indicate that both methods that apply residual kriging correction were influenced by outlier stations. This is evidenced by 2 particular regions with high precipitation in the Andes in the August maps of $P_{R K T}$ and $P_{R K T C}$, where in situ stations with high precipitation records are located.

\subsection{Validation Over In Situ Data}

\subsubsection{Summary Statistics}

A summary of RMSE, PBIAS and $R^{2}$ values between in situ time series and the time series of the 5 products obtained in the corresponding stations are presented in this section. The statistical values are presented in Table 1, where the statistics of $P_{T 0.25^{\circ}}$ have also been included. Other than a finer grid, no information is added to the original TRMM images by means of bilinear resampling. Thus, as expected, no significant differences are observed between $P_{T 0.25^{\circ}}$ and $P_{T 5}$ in terms of error. Therefore, hereafter, comparisons are only made among the dowsncaled products. 
Table 1. Median and interquartile range $(I Q R)$ values of the statistics for the original TRMM images and the five dowsncaled products in the three regions for the 132 months between 2001 and 2011.

\begin{tabular}{|c|c|c|c|c|c|c|c|}
\hline & & \multicolumn{2}{|c|}{ RMSE } & \multicolumn{2}{|c|}{ PBIAS } & \multicolumn{2}{|c|}{$R^{2}$} \\
\hline & & Median & $I Q R$ & Median & $I Q R$ & Median & $I Q R$ \\
\hline \multirow{6}{*}{ Coast } & $P_{T 0.25^{\circ}}$ & 66.03 & 29.76 & -14.6 & 35.9 & 0.85 & 0.19 \\
\hline & $P_{T 5}$ & 61.99 & 32.45 & -10.60 & 40.20 & 0.85 & 0.19 \\
\hline & CV-P $P_{R T}$ & 61.31 & 46.20 & -14.80 & 32.20 & 0.82 & 0.12 \\
\hline & CV-P $P_{R K T}$ & 58.75 & 24.53 & 7.70 & 34.00 & 0.84 & 0.16 \\
\hline & CV-P $P_{R T C}$ & 64.33 & 45.65 & -8.70 & 40.00 & 0.83 & 0.16 \\
\hline & CV-P $P_{\text {RKTC }}$ & 59.18 & 26.33 & 9.80 & 37.00 & 0.85 & 0.17 \\
\hline \multirow{6}{*}{ Andes } & $P_{T 0.25^{\circ}}$ & 58.66 & 25.38 & 22.75 & 84.15 & 0.57 & 0.34 \\
\hline & $P_{T 5}$ & 56.96 & 22.45 & 22.35 & 89.70 & 0.56 & 0.35 \\
\hline & CV-P $P_{R T}$ & 51.75 & 35.93 & -10.00 & 57.90 & 0.63 & 0.31 \\
\hline & $C V-P_{R K T}$ & 46.58 & 26.37 & 9.85 & 58.23 & 0.58 & 0.23 \\
\hline & CV-P $P_{R T C}$ & 49.04 & 35.02 & -10.35 & 48.60 & 0.64 & 0.27 \\
\hline & CV-P $P_{R K T C}$ & 44.92 & 25.26 & 5.20 & 44.53 & 0.61 & 0.23 \\
\hline \multirow{6}{*}{ Amazon } & $P_{T 0.25^{\circ}}$ & 70.53 & 41.05 & 2.10 & 17.20 & 0.40 & 0.37 \\
\hline & $P_{T 5}$ & 80.85 & 50.61 & -3.25 & 23.18 & 0.41 & 0.38 \\
\hline & CV-P $P_{R T}$ & 125.27 & 87.19 & -30.40 & 17.00 & 0.26 & 0.10 \\
\hline & CV-P $P_{R K T}$ & 117.94 & 63.06 & -1.55 & 28.70 & 0.27 & 0.14 \\
\hline & $\mathrm{CV}-P_{R T C}$ & 113.23 & 70.97 & -5.00 & 23.28 & 0.30 & 0.14 \\
\hline & CV-P $P_{\text {RKTC }}$ & 96.93 & 61.67 & 5.55 & 31.80 & 0.33 & 0.16 \\
\hline
\end{tabular}

\section{Coast Region}

In Figure 6a, the cross-validation results for the stations in the Coast are presented. In 3 out of 4 products, a reduction in median RMSE was observed with respect to $P_{T 5}$. The largest reduction was obtained with $P_{R K T}(5 \%)$, followed by $P_{R K T C}(4 \%)$ and $P_{R T}(1 \%)$. Therefore, slight improvements were observed by both methods that apply residual kriging correction, outperforming the regression models. Furthermore, in the products resulting from these two methods, $P_{T 5} R M S E$ dispersion, particularly in higher values, was reduced. The IQR decreased by $24 \%$ in $P_{R K T}$ and by $19 \%$ in $P_{R K T C}$ (refer to Table 1 when values are specified).

Regarding PBIAS, in 3 out of 4 products, a reduction in absolute median PBIAS was observed when compared to $P_{T 5}$. However, only the regression kriging methods resulted in positive median PBIAS. The smallest and positive PBIAS was produced by $P_{R K T}(7.7)$, followed by $P_{R K T C}(9.8)$. With respect to $P_{T 5}$, the $I Q R$ values indicate that $P B I A S$ dispersion was reduced by all 4 methods from step 2 , where $P_{R K T}$ produced the largest reduction (15\%), followed by $P_{R K T C}(8 \%)$.
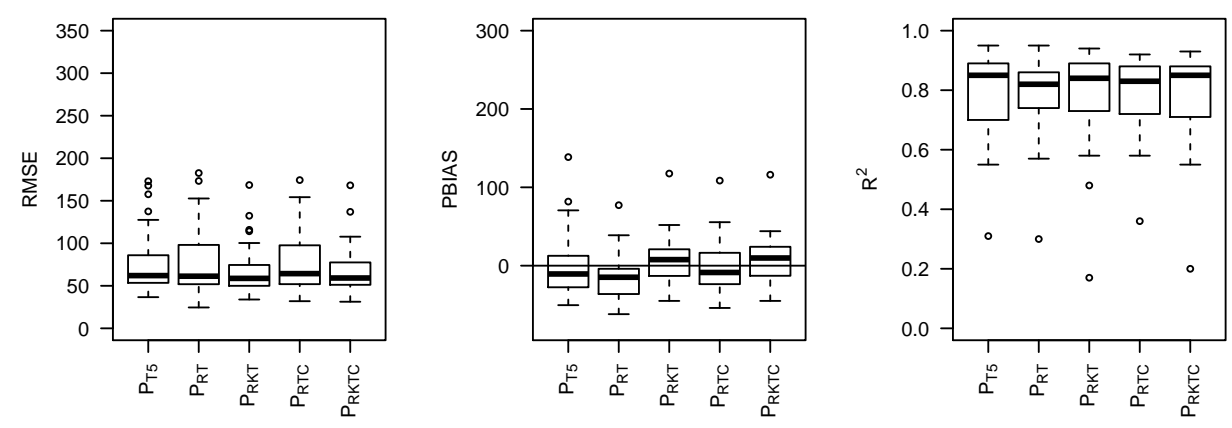

(a)

Figure 6. Cont. 

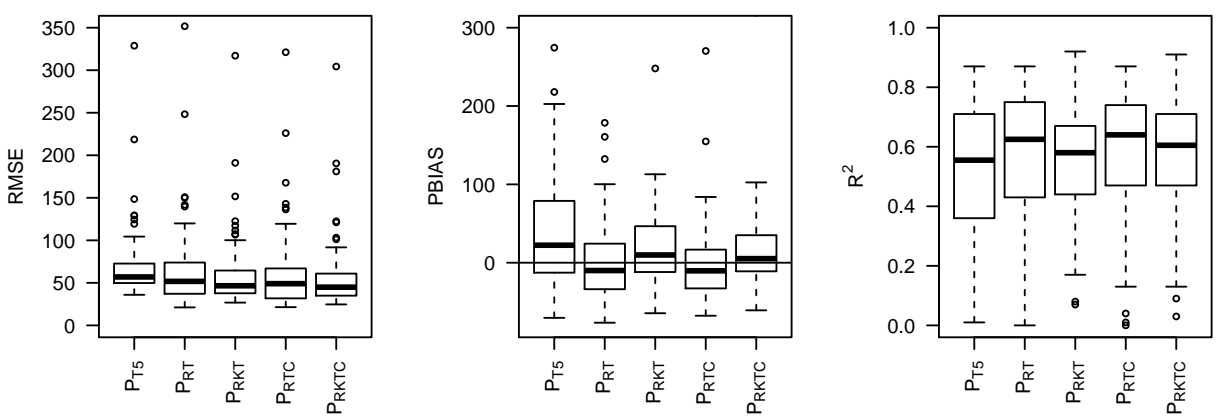

(b)
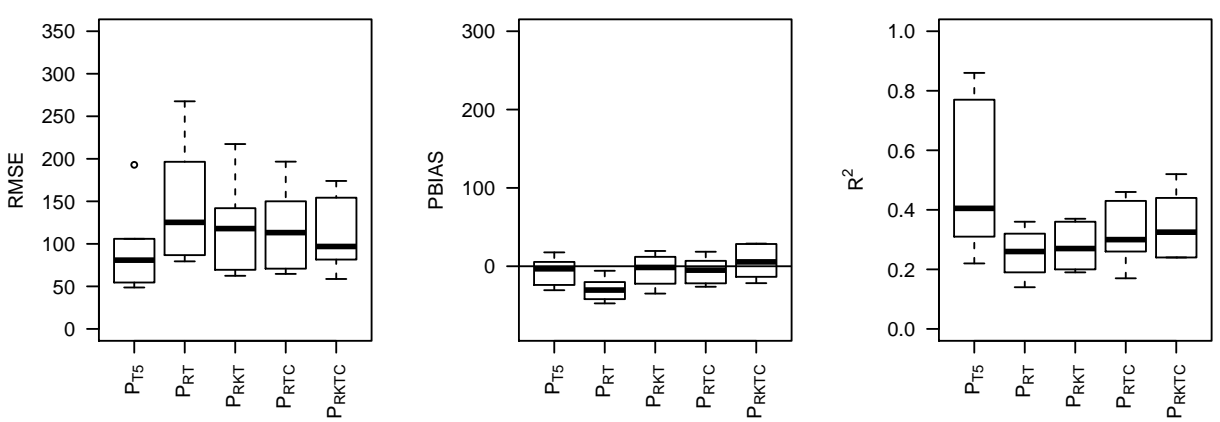

(c)

Figure 6. Summary of statistical values: (a) Coast region; (b) Andes region; (c) Amazon region.

Previous works (e.g., [15]) have reported that, in the coastal plains, TRMM images appropriately capture seasonality, which can be measured by $R^{2}$ values. Therefore, it was expected to find no improvement in time series correlations with respect to $P_{T 5}$. In all 5 cases, median $R^{2}$ was higher than 0.80 , with the lowest value for $P_{R T}$. In addition, relatively low $I Q R$ values result from the 5 products; thus, the results from the 2-step products were consistent with the expected seasonality accuracy of TRMM in this region.

\section{Andes Region}

In Figure $6 \mathrm{~b}$, the cross-validation results for the stations in the Andes are presented. In all 4 products that incorporate step 2, an overall reduction in median RMSE was observed with respect to $P_{T 5}$. The largest reduction was observed for $P_{R K T C}(21 \%)$, followed by $P_{R K T}(18 \%), P_{R T C}(14 \%)$ and $P_{R T}(9 \%)$. However, it should be noted that the $I Q R$ values show that $R M S E$ dispersion was slightly increased by all 2-step products with respect to $P_{T 5}$.

The PBIAS of $P_{T 5}$ indicates an important overestimation (median value of 22.35), which was reduced by the methods from step 2. Nevertheless, negative median PBIAS was obtained by $P_{R T}$ $(-10.00)$ and $P_{R T C}(-10.35)$. The smallest and positive median PBIAS corresponds to $P_{R K T C}(5.20$, reducing $P_{T 5}$ PBIAS by $77 \%$ ) followed by $P_{R K T}\left(9.85\right.$, reducing $P_{T 5} P B I A S$ by $\left.56 \%\right)$. This can be observed in Figure $6 \mathrm{~b}$, in which both products with residual kriging correction present small and positive median $P B I A S$. Regarding the $I Q R, P_{T 5}$ presents a value of 89.70 , which was notably reduced by the 2-step products. $P_{R K T C}$ presents the largest IQR reduction with respect to $P_{T 5}$ (by $50 \%$ ). According to these results, the largest improvement in terms of bias was observed when auxiliary variables were included and residual kriging correction was applied. Therefore, the information 
provided by land and atmospheric variables played a mayor role in increasing the accuracy of $P_{T 5}$ in this region.

The accuracy of the seasonality of $P_{T 5}$ in the Andes is significantly lower than in the Coast, which is an expected result, given the complex topography of the region. For the 2-step products, median $R^{2}$ values were higher than for $P_{T 5}(0.56)$. However, the improvement achieved was small, with the larger improvement given by $P_{R T C}$, with a median $R^{2}$ of 0.64 . In addition, IQR was most notably reduced from 0.35 in $P_{T 5}$ to 0.23 in both $P_{R K T}$ and $P_{R K T C}$.

\section{Amazon Region}

The Amazon region presents the largest $R M S E$ of $P_{T 5}$ among the 3 regions (median value of 80.85 for $\left.P_{T 5}\right)$. The 2-step products increased $R M S E$ with respect to $P_{T 5}$, where $P_{R K T C}$ produced the smallest increase (20\%). Similar to RMSE, PBIAS did not show a clear improvement. Although $P_{R K T C}$ was the only product that achieved a positive median PBIAS, its absolute value (5.55) was larger than for $P_{T 5}$ (-3.25). $P_{R K T C}$ reported a negative PBIAS of -1.55 , which reduced the value of the reference product. In addition, $R^{2}$ values decreased in all 4 products. These results indicate that the performance of the resampled TRMM data set notably decreases in the Amazon, and no improvements are provided by the methods from step 2 . Nevertheless, it should be noted that these results are strongly influenced by the low number of stations in the region.

\subsubsection{Spatial Analysis}

In the previous section, a summary of the validation over the stations was presented by summary statistical values. In this section, the spatial distribution of the statistic values is described, and is presented in Figures 7-9.
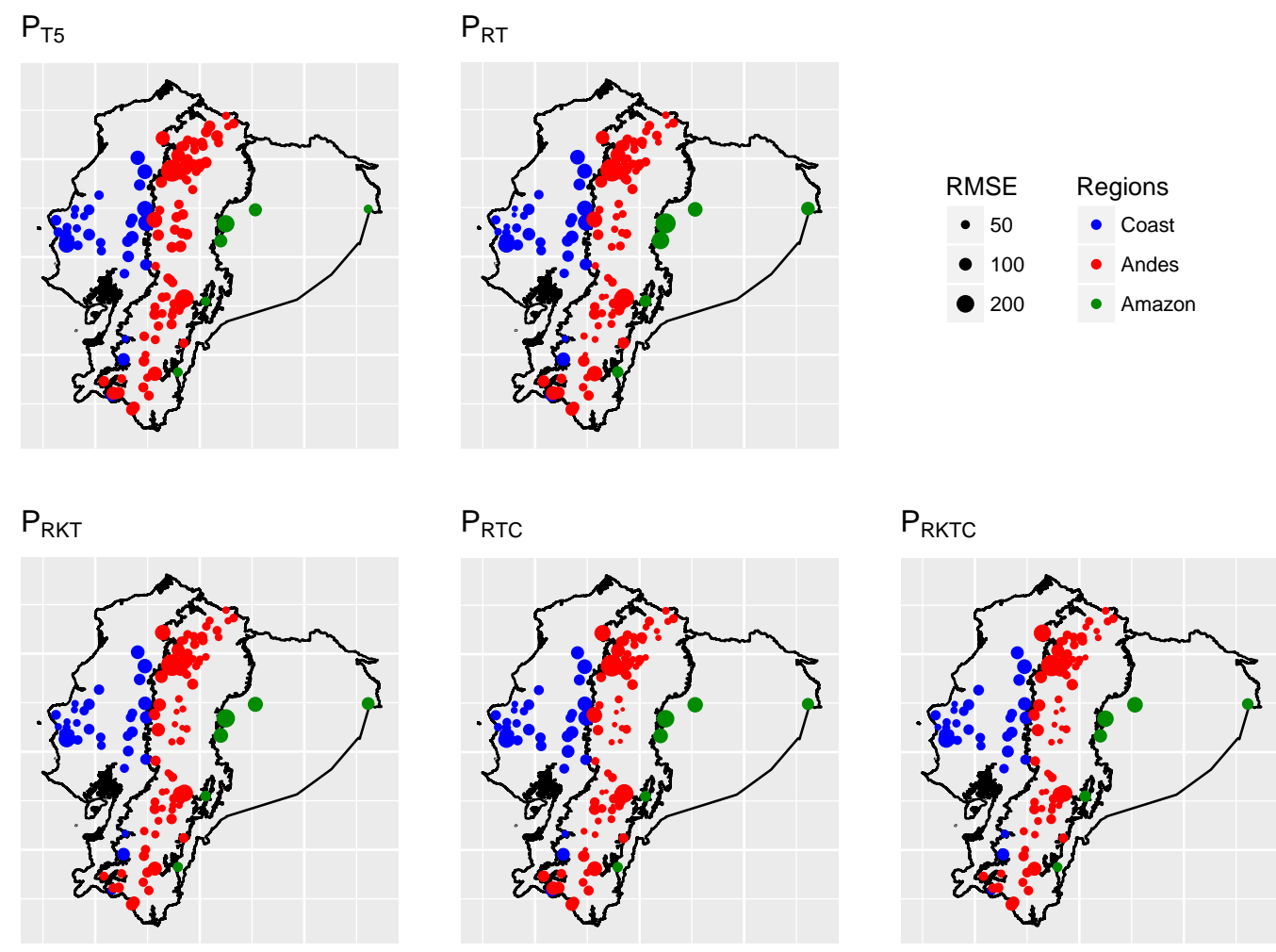

Figure 7. RMSE of the five products over the station points. 
$\mathrm{P}_{\mathrm{T5}}$

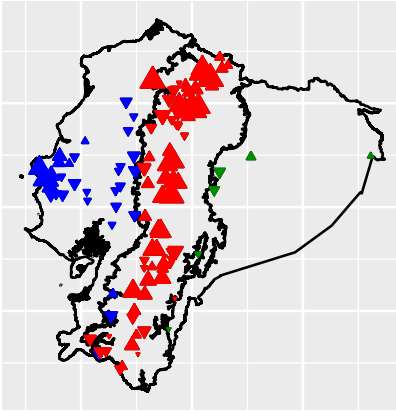

$P_{\text {RKT }}$

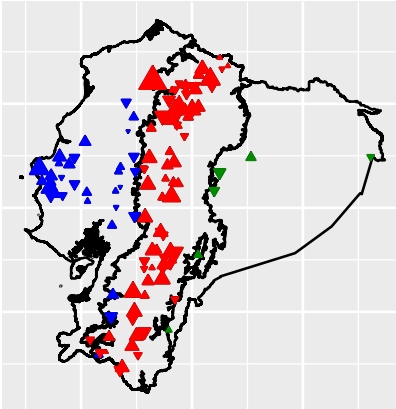

$P_{R T}$

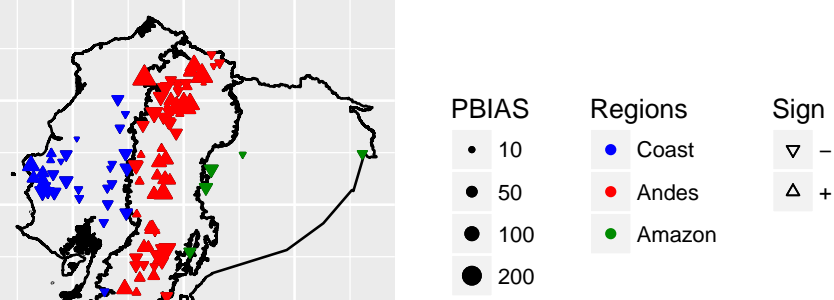

$P_{\text {RTC }}$

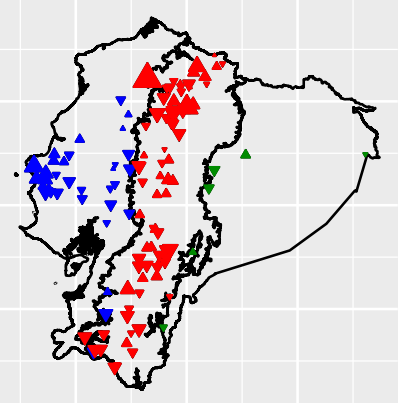

$\mathrm{P}_{\text {RKTC }}$

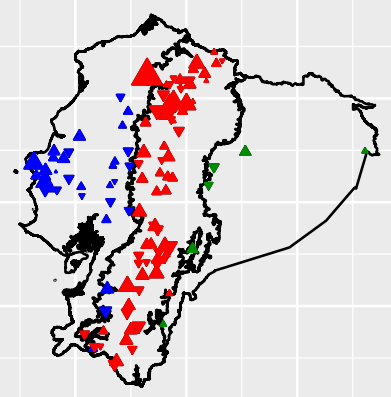

Figure 8. $P B I A S$ of the five products over the station points.

$\mathrm{P}_{\mathrm{T5}}$

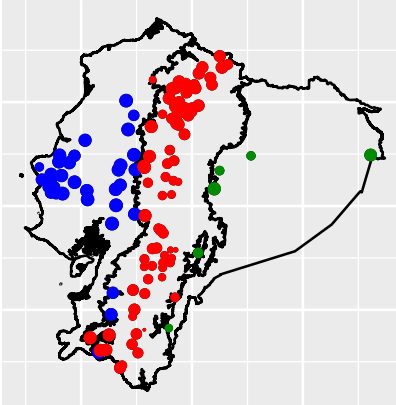

$P_{\text {RKT }}$

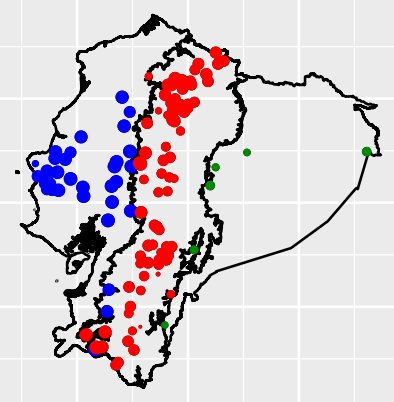

$P_{R T}$
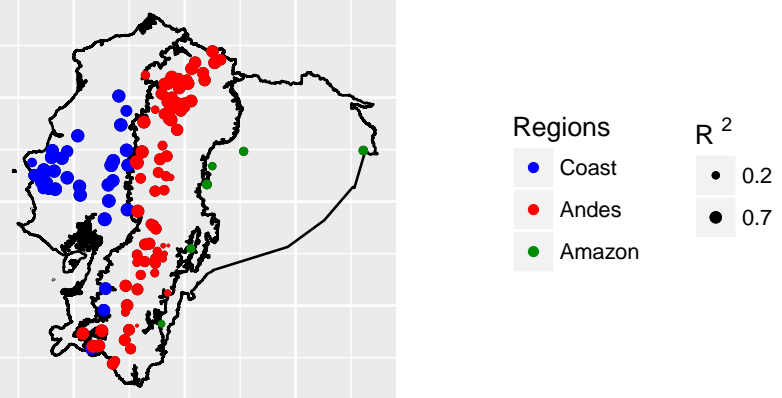

$P_{\text {RTC }}$

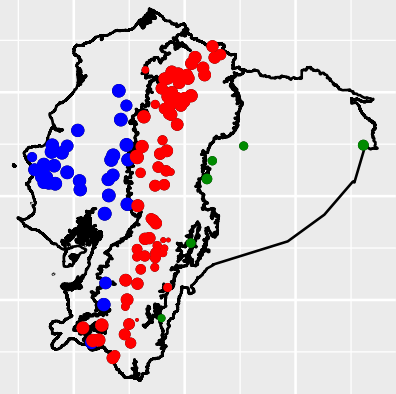

$P_{\text {RKTC }}$

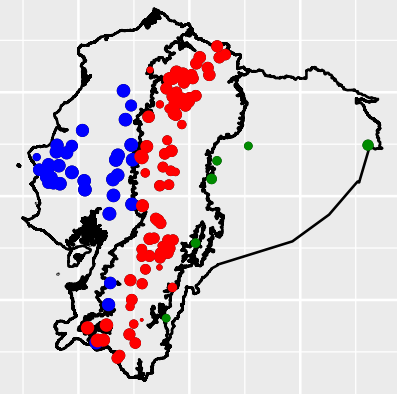

Figure 9. $R^{2}$ of the five products over the station points. 


\section{Coast Region}

Figure 7 shows the RMSE values over the study region. In the Coast, all products exhibit a similar RMSE distribution pattern. Lower values are observed in the central part of the Coast, while higher values lie along the $1000 \mathrm{~m}$ a.s.l. eastern borderline, as well as the western coastal border. In the maps from Figure 8, smaller and mainly negative PBIAS values are located in central Coast, while higher and positive values are observed close to the western coastal border. Large negative values lie along the $1000 \mathrm{~m}$ a.s.l. borderline. Thus, precipitation was overestimated towards the west and underestimated in regions close to the western slopes of the cordillera. In $P_{R K T}$, it can be observed that several points shift from negative to positive PBIAS, along with a decrease in absolute value. Finally, Figure 9, shows that high $R$ values are evenly distributed all over the Coast, with slightly lower values along the eastern borderline.

\section{Andes Region}

In Figure 7, it can be observed that all products produced a similar RMSE distribution pattern across the Andes. Larger values are present in distinctive regions in the north and in the south, and smaller values lie along the interandean valleys, running from north to south through the central Andes region. The maps show that, compared to $P_{T 5}, R M S E$ is improved by the regression kriging methods; however, the inclusion of auxiliary variables, even for the regression models, produced a more consistent improvement throughout the region, particularly in the central Andes. The maps from Figure 8 show larger PBIAS values towards the north, and smaller values in the center of the interandean valleys, where a significant reduction can be observed for $P_{R T C}$ and $P_{R K T C}$. Thus, the products with auxiliary variables tend to reduce RMSE and PBIAS with a similar spatial pattern. Finally, Figure 9 indicates that generally, the regression kriging methods tend to increase $R^{2}$ values in particular regions, and the products with auxiliary variables result in a more consistent correlation improvement throughout the Andes. For the 5 products, high $R^{2}$ values are present in the north and the southwest of the region. On the other hand, lower values lie along the interandean valleys, where, by contrast, better results were observed in terms of RMSE and PBIAS. Thus, it would be desirable to improve the mapping methods to also increase these $R^{2}$ values.

\section{Amazon Region}

The maps from Figures 7-9 show the sparse and uneven distribution of in situ stations in the Amazon region. In $P_{T 5}$, the 5 stations close to the cordillera show large RMSE, moderate PBIAS and low $R^{2}$ values. The station located on the eastern border presents lower RMSE and higher $R^{2}$ values, indicating that the results of the region are highly influenced by the location of the majority of the stations. These results are not improved by any of the methods that incorporate step 2.

\section{Results Summary and Discussion}

In this work, the validation results over 117 stations indicate that the performance of the resampled TRMM 3B43 V7 data set and its potential improvements with 2-step downscaling vary among climatic regions, and no single product outperforms the others in every region. The 2-step methodology is somehow reminiscent of the methodology used in [38,39], although the application in these references was different: downscaling of general circulation models' results. The results obtained in those works showed a significant skill in describing both climatology and anomalies.

Regarding spatiotemporal variability, the 5 products generally captured the different regimes of the climatic regions. However, different patterns were observed. The downscaled maps show that the inclusion of auxiliary variables in step 2 introduces spatial variation that was not captured by the methods without auxiliary variables. This represents an important enhancement over $P_{T 5}$ throughout the year, particularly in the Andes, where the complex topography imposes significant limitations for TRMM accuracy. On the other hand, the methods that apply of residual kriging correction played 
an important role in adjusting predictions to observed values. However, it should be noted that these methods might be significantly influenced by outlier stations. For instance, in a dry month (e.g., August), distinctive regions of high precipitation can be observed in the neighborhood of stations that present high precipitation throughout the year. Therefore, careful attention should be given to the presence of outliers in the observed data when regression kriging is applied because large residuals might spread across the neighborhood of outlier stations. These qualitative observations were analyzed in this work by summary statistics and the spatial distribution interpretation.

In the Coast, $P_{T 5}$ has a wide error deviation and underestimates precipitation. This is consistent with [32], where the climatological maps showed that western Ecuador is underestimated by TRMM. This behavior was improved by the step 2 methods, where $P_{R K T}$ and $P_{R K T C}$ showed to be better products than those which did not apply residual kriging correction, reducing both RMSE and PBIAS. Additionally, they provided positive PBIAS, which may induce false-positive flooding risk events that are less harmful than false-negative. Between both regression kriging products, $P_{R K T}$ yielded the best results. Thus, residual kriging correction over $P_{T 5}$ performed better, and obtaining information from auxiliary variables, as in $P_{R K T C}$, which may be time-consuming, is not a worthwhile contribution for spatial predictions in the Coast. On the other hand, the seasonal features of this region are well-captured by $P_{T 5}$, as evidenced by consistently high $R^{2}$ values. These results build upon the findings of [15], where 14 stations were used for TRMM validation. Improvements over the reference product in terms of seasonality in the Coast were not observed by any of the 4 methods that incorporate step 2, yielding only similar performance.

The performance of $P_{T 5}$ in the Andes is considerably decreased, which is a well-known effect of the complex topography of the region. An important overestimation of $P_{T 5}$ was found with respect to ground measurements. This is consistent with previous findings. For instance, [40] reported that, with respect to its predecessor (TRMM 3B43 V6), TRMM 3B43 V7 reduced negative bias, but resulted in overestimation in the Andes. In this region, as opposed to the Coast, the effect of including auxiliary variables is noteworthy. $P_{R K T C}$ outperformed the other products, showing that the use of auxiliary variables combined with residual kriging correction plays a major role in generating downscaled products with low RMSE and PBIAS in regions with complex topography. While the overall modest correlation of $P_{T 5}$ was only slightly increased, errors were widely reduced. Regarding RMSE, along the interandean valleys, the products with auxiliary variables generally outperformed the ones that only use $P_{T 5}$. In addition, the overestimation of $P_{T 5}$ was significantly reduced by $P_{R K T C}$ (77\% reduction with respect to $\left.P_{T 5}\right)$. Note that, in terms of bias, $P_{R K T C}$ in the Andes performed better than the best-performing product in the Coast $\left(P_{R K T}\right)$. This, however, can be attributed to the denser network station in the Andes. Nevertheless, these results suggest that the information provided by auxiliary variables accounts for spatial variation that is not captured by TRMM due to the difficulties imposed by the topographical features and could be very useful for generating fine-scaled spatially continuous precipitation fields in mountain regions.

Finally, for the Amazon region, no improvement was observed by the 2-step products with respect to $P_{T 5}$. Nevertheless, it should be noted that these results are influenced by the low number of stations in the region. The lack of in situ data and the closeness to the cordillera of 5 out of 6 stations represent a significant drawback for the methods in step 2, resulting in poor predictions. Additionally, the uneven distribution of the stations introduces further uncertainty in the validation procedure. For these reasons, these results are considered inconclusive, which highlights the need to implement a monitoring network in the Amazon.

Previous downscaling works have mostly applied downscaling to $1 \mathrm{~km}$ at an annual time scale. Nevertheless, the performance of the products generated therein can be (roughly) contrasted with the performance of the $5 \mathrm{~km}$ downscaled monthly products generated in this paper. For instance, [25] reported that exploiting the local relationship between auxiliary variables and precipitation in North China yields promising results, where GWR performed better than the methodology proposed by $[9,24]$. Although complex topography and strong precipitation gradients 
are present in the North China region, there is a clear seasonal precipitation pattern [25], which is clearly not the case of Ecuador due to the contrasting climatic regions. Nevertheless, the statistical results of [25] are similar to the results obtained in this study for the Andes region. With respect to TRMM, a decrease in both RMSE and bias was reported, along with no improvement in terms of $R^{2}$. Although applying local relationships between precipitation and auxiiliary variables has produced promising results, no improvement was observed in this work by applying the methods from step 2 in the Coast and Andes regions independently (to avoid redundancy, these results were not shown). However, future studies may consider applying GWR. Regarding machine learning procedures, [27] reported that post-calibration of the downscaled TRMM images reduces RMSE and bias, which is also consistent with the results obtained in this study. Finally, [28] also reported improvements over TRMM using machine learning techniques. However, accuracy was decreased after applying residual correction using TRMM at the original resolution as the dependent variable and spline interpolation. In contrast, in this work, residual correction significantly improved the results using the observed data as the dependent variable and kriging interpolation.

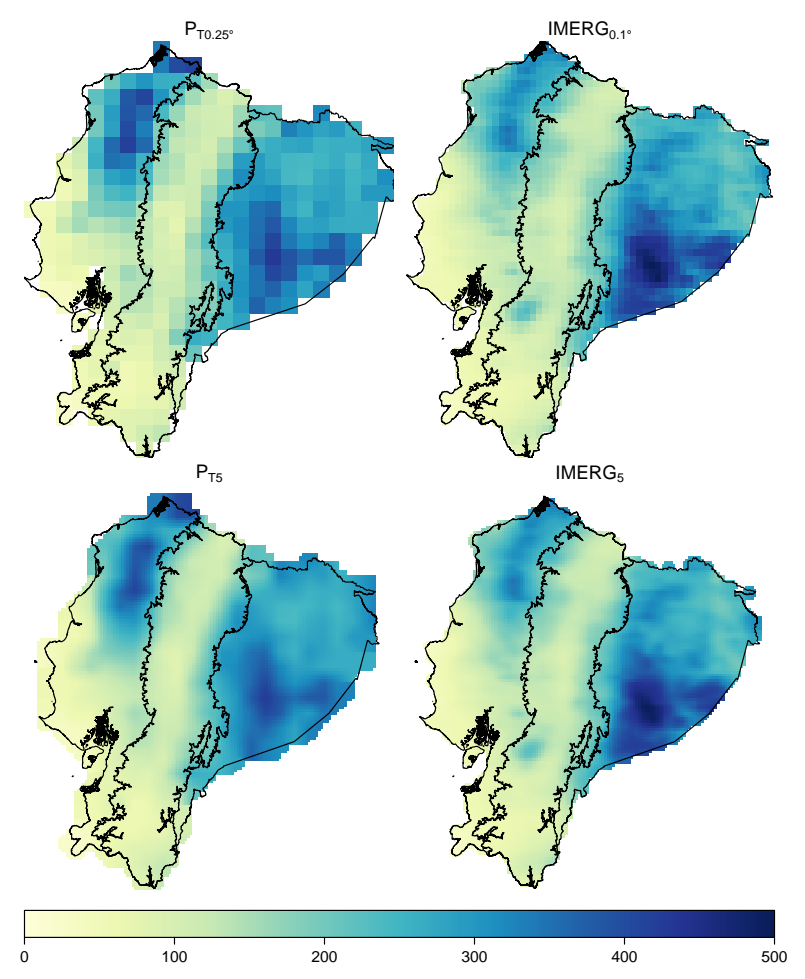

Figure 10. Monthly precipitation [mm] of April 2014 for the TRMM product and IMERG, both at their native resolution and resampled to $5 \mathrm{~km}$.

The methodology proposed in this work was applied to TRMM satellite precipitation from 2001 to 2011 with a spatial resolution of $0.25^{\circ}$. In the considered period, both satellite auxiliary variables and in situ observations were available. However, since TRMM was turned off in 2015, and having in mind the availability of an up-to-date downscaled precipitation product, it becomes relevant to explore if the proposed downscaling approach would succeed with other satellite precipitation products. This might be the case of the recently launched GPM Core Satellite, with its IMERG product available at a resolution of $0.1^{\circ}$. Therefore, the first step of the downscaling approach was applied on TRMM and IMERG for April and August 2014, where both products were available. Figures 10 and 11, corresponding to the months of April 2014 and August 2014, respectively, show the images at their native resolutions as well as the resampled resolution of $5 \mathrm{~km}$ (the resampled IMERG images 
are referred to as $I M E G R_{5}$ ). It can be observed that both resampled images show similar spatial precipitation patterns and variability. Furthermore, Figure 12 displays a $5 \times 5$ moving window correlation between the resampled images. It shows high correlations all over Ecuador with a mean correlation in April of 0.80 and in August of 0.88 . This is indicative of the possibility of applying the first step of our downscaling approach to the IMERG product. The second step needs to be tested in further research, but the result presented here shows the plausibility of the approach proposed in this paper when applied to the IMERG product.

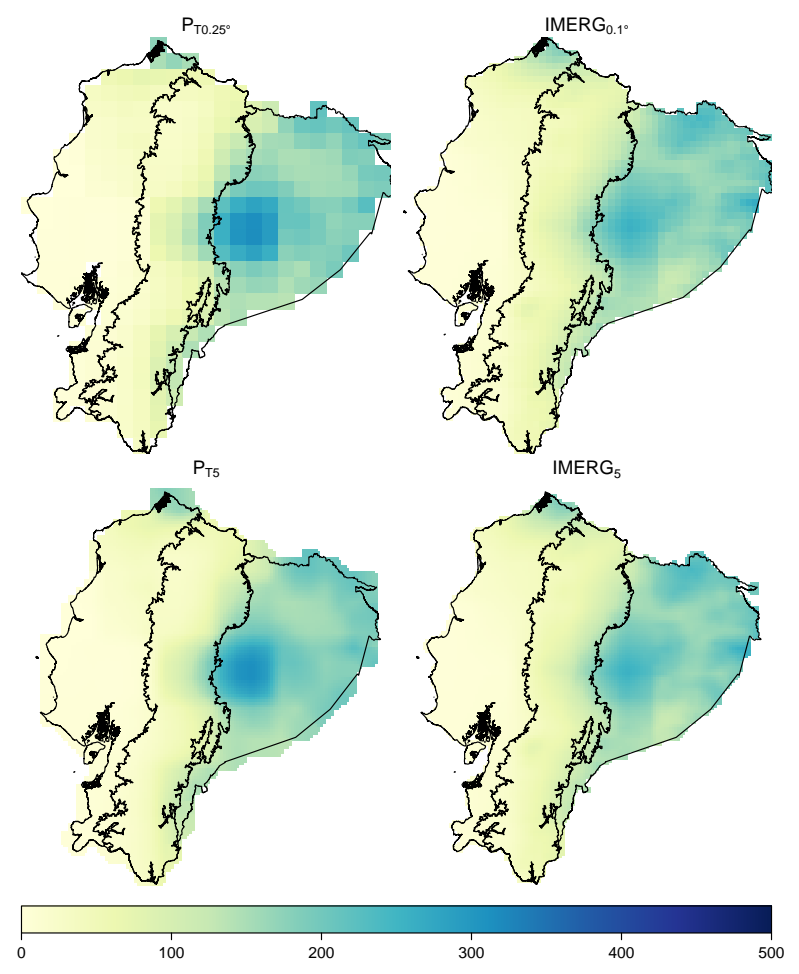

Figure 11. Monthly precipitation [mm] of August 2014 for the TRMM product and IMERG, both at their native resolution and resampled to $5 \mathrm{~km}$.

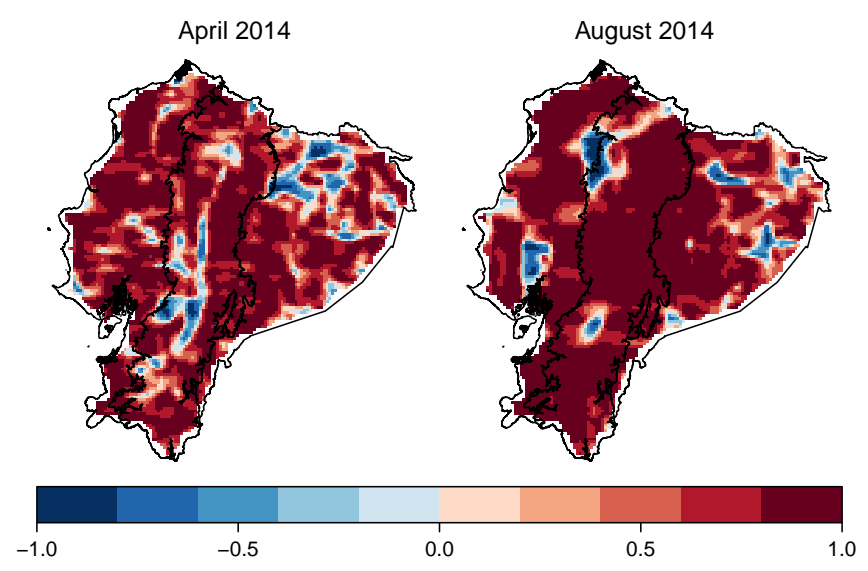

Figure 12. $5 \times 5$ moving window correlation between the TRMM product and IMERG resampled to $5 \mathrm{~km}$. 


\section{Conclusions}

Two-step downscaling approaches have been carried out for the mapping of precipitation at a $5 \mathrm{~km}$ resolution in the continental territory of Ecuador. Due to the fact that this country presents the Coast, the Andes and the Amazon regions, the methods could be validated in contrasting climatic regions, which is of great value for evaluation purposes. The first step, consisting of bilinear resampling over the TRMM 3B43 V7 data set, was validated. Then, potential enhancements were explored by step 2, which consists of 4 alternative gauge-satellite merging methods: exponential regression and regression kriging with the resampled TRMM images, and exponential regression and regression kriging with the resampled TRMM images and auxiliary variables. With respect to TRMM 3B43 V7, the $5 \mathrm{~km}$ monthly products generated in this study constitute an enhanced source of downscaled spatially continuous precipitation data. By applying a simple resampling technique and merging satellite-born data with in situ data, TRMM measurements downscaled and calibrated. The cross-validation analysis revealed that the inclusion of cloud top temperature, cloud fraction, NDVI and soil moisture in a selective procedure reduces both bias and error deviation in the Andes and in coastal regions close to the cordillera. Additionally, time series correlation is slightly increased. On the other hand, regression kriging produced more improvement in the Coast. In this region, the TRMM resampled images perform very well in terms of seasonality, and the inclusion of auxiliary variables seems to introduce noise. Only the stations close to the eastern slopes of the cordillera showed improvement in PBIAS with the multivariate models, which confirms the influence of auxiliary variables in regions with complex topography. In the Amazon region, no product outperformed the resampled TRMM data set. This, however, is considered inconclusive due to the low number of in situ stations and their uneven distribution, stressing the need for a monitoring network in the region.

Although improvements over the resampled TRMM data set were observed, there is still uncertainty in precipitation estimates in the study area. Data from a denser motoring network should be used to improve estimations in certain regions, such as the western slopes of the cordillera and the northern Andes. Most importantly, the lack of data in the Amazon is a significant inconvenience; TRMM and its potential enhancements can not be properly analyzed. Despite these limitations, future studies could be conducted. Because of the different performance of TRMM and the improved 2-step downscaled products in the 3 regions, a more detailed regionalization than the 3 climatic regions could be defined for independent analysis. Also, GWR can be tested to further exploit the local relationship between precipitation and auxiliary variables. In addition, the methodology can be approached in a different manner. For instance, machine learning downscaling algorithms with the fine-scale auxiliary variables can be applied as step 1, with gauge calibration as step 2.

Acknowledgments: The current study has been founded by DIUC - Universidad de Cuenca through the project "Spatial sampling optimization of precipitation with multivariate geostatistics".

Author Contributions: In this study, Jacinto Ulloa and Daniela Ballari conceived and designed the numerical experiments. Jacinto Ulloa performed the numerical experiments and analyzed the results along with Daniela Ballari, Lenin Campozano, and Esteban Samaniego, who all contributed with analysis tools. Lenin Campozano contributed with climatological interpretations. Jacinto Ulloa wrote the manuscript, while the three co-authors contributed with reviews.

Conflicts of Interest: The authors declare no conflict of interest. The founding sponsors had no role in the design of the study; in the collection, analyses, or interpretation of data; in the writing of the manuscript, and in the decision to publish the results.

\section{Abbreviations}

The following abbreviations are used in this manuscript: 
CTT Could top temperature monthly images for the study area at $5 \mathrm{~km}$

CF Could fraction monthly images for the study area at $5 \mathrm{~km}$

NDVI Normalized Vegetation Index monthly images for the study area at $5 \mathrm{~km}$

$S M \quad$ Soil moisture monthly images for the study area at $5 \mathrm{~km}$

$P_{T 0.25^{\circ}} \quad$ Original TRMM 3B43 V7 images

$P_{T 5} \quad$ TRMM 3B43 V7 images resampled to $5 \mathrm{~km}$

$I M E R G_{0.1^{\circ}}$ Original IMERG precipitation images

$I_{M E R G_{5}}$ IMERG precipitation images resampled to $5 \mathrm{~km}$

$P_{R T} \quad$ Product from a regression model with in situ data using $P_{T 5}$ as the independent variable

$P_{R K T} \quad$ Product from a regression kriging model with in situ data using $P_{T 5}$ as the independent variable

$P_{R T C} \quad$ Product from a regression model with in situ data using $P_{T 5}$ and auxiliary variables

$P_{R K T C} \quad$ Product from a regression kriging model with in situ data using $P_{T 5}$ and auxiliary variables

\section{References}

1. Hunink, J.; Immerzeel, W.; Droogers, P. A High-resolution Precipitation 2-step mapping Procedure (HiP2P): Development and application to a tropical mountainous area. Remote Sens. Environ. 2014, 140, 179-188.

2. Cheema, M.J.M.; Bastiaanssen, W.G. Local calibration of remotely sensed rainfall from the TRMM satellite for different periods and spatial scales in the Indus Basin. Int. J. Remote Sens. 2012, 33, 2603-2627.

3. Buytaert, W.; Celleri, R.; Willems, P.; De Bievre, B.; Wyseure, G. Spatial and temporal rainfall variability in mountainous areas: A case study from the south Ecuadorian Andes. J. Hydrol. 2006, 329, 413-421.

4. Immerzeel, W.W.; Pellicciotti, F.; Shrestha, A.B. Glaciers as a proxy to quantify the spatial distribution of precipitation in the Hunza basin. Mt. Res. Dev. 2012, 32, 30-38.

5. Xie, P.; Xiong, A.Y. A conceptual model for constructing high-resolution gauge-satellite merged precipitation analyses. J. Geophys. Res. Atmos. 2011, 116, doi:10.1029/2011JD016118.

6. Rossel, F.; Le Goulven, P.; Cadier, E. Areal distribution of the influence of ENSO on the annual rainfall in Ecuador [El Nino/Southern oscillation]. Revue des Sciences de l'Eau 1999, 12, 183-200.

7. Padrón, R.S.; Wilcox, B.P.; Crespo, P.; Célleri, R. Rainfall in the Andean Páramo: new insights from high-resolution monitoring in Southern Ecuador. J. Hydrometeorol. 2015, 16, 985-996.

8. Fang, J.; Du, J.; Xu, W.; Shi, P.; Li, M.; Ming, X. Spatial downscaling of TRMM precipitation data based on the orographical effect and meteorological conditions in a mountainous area. Adv. Water Resour. 2013, $61,42-50$.

9. Immerzeel, W.; Rutten, M.; Droogers, P. Spatial downscaling of TRMM precipitation using vegetative response on the Iberian Peninsula. Remote Sens. Environ. 2009, 113, 362-370.

10. Tobin, K.J.; Bennett, M.E. Adjusting satellite precipitation data to facilitate hydrologic modeling. J. Hydrometeorol. 2010, 11, 966-978.

11. Chen, Y.; Ebert, E.E.; Walsh, K.J.; Davidson, N.E. Evaluation of TRMM 3B42 precipitation estimates of tropical cyclone rainfall using PACRAIN data. J. Geophys. Res. Atmos. 2013, 118, 2184-2196.

12. Ji, Y.; Stocker, E. Ground validation of TRMM and AMSU microwave precipitation estimates. In Proceedings of the 2003 IEEE International Geoscience and Remote Sensing Symposium (IGARSS 2003), Toulouse, France, 21-25 July 2003; Volume 5, pp. 3157-3159.

13. Chokngamwong, R.; Chiu, L. TRMM and Thailand daily gauge rainfall comparison. Am. Meteorol. Soc. Atlanta Georgia 2006, 10, 1-2.

14. Ochoa, A.; Pineda, L.; Crespo, P.; Willems, P. Evaluation of TRMM $3 B 42$ Precipitation Estimates and WRF Retrospective Precipitation Simulation Over the Pacific-Andean Region of Ecuador and Peru; European Geophysical Society: Munich, Germany, 2014.

15. Ballari, D.; Castro, E.; Campozano, L. Validation of Satellite Precipitation (trmm 3B43) in Ecuadorian Coastal Plains, Andean Highlands and Amazonian Rainforest. ISPRS Int. Arch. Photogramm. Remote Sens. Spat. Inf. Sci. 2016, 41, 305-311.

16. Goovaerts, P. Geostatistical approaches for incorporating elevation into the spatial interpolation of rainfall. J. Hydrol. 2000, 228, 113-129.

17. Celleri, R.; Willems, P.; Buytaert, W.; Feyen, J. Space-time rainfall variability in the Paute basin, Ecuadorian Andes. Hydrol. Process. 2007, 21, 3316-3327. 
18. Ichii, K.; Kawabata, A.; Yamaguchi, Y. Global correlation analysis for NDVI and climatic variables and NDVI trends: 1982-1990. Int. J. Remote Sens. 2002, 23, 3873-3878.

19. Wang, J.; Price, K.; Rich, P. Spatial patterns of NDVI in response to precipitation and temperature in the central Great Plains. Int. J. Remote Sens. 2001, 22, 3827-3844.

20. Bendix, J.; Rollenbeck, R.; Göttlicher, D.; Cermak, J. Cloud occurrence and cloud properties in Ecuador. Clim. Res. 2006, 30, 133-147.

21. Campozano, L.; Célleri, R.; Trachte, K.; Bendix, J.; Samaniego, E. Rainfall and cloud dynamics in the Andes: A southern Ecuador case study. Adv. Meteorol. 2016, doi:10.1155/2016/3192765.

22. Diodato, N. The influence of topographic co-variables on the spatial variability of precipitation over small regions of complex terrain. Int. J. Climatol. 2005, 25, 351-363.

23. Ninyerola, M.; Pons, X.; Roure, J.M. A methodological approach of climatological modelling of air temperature and precipitation through GIS techniques. Int. J. Climatol. 2000, 20, 1823-1841.

24. Jia, S.; Zhu, W.; Lü, A.; Yan, T. A statistical spatial downscaling algorithm of TRMM precipitation based on NDVI and DEM in the Qaidam Basin of China. Remote Sens. Environ. 2011, 115, 3069-3079.

25. Chen, F.; Liu, Y.; Liu, Q.; Li, X. Spatial downscaling of TRMM 3B43 precipitation considering spatial heterogeneity. Int. J. Remote Sens. 2014, 35, 3074-3093.

26. Shi, Y.; Song, L.; Xia, Z.; Lin, Y.; Myneni, R.B.; Choi, S.; Wang, L.; Ni, X.; Lao, C.; Yang, F. Mapping annual precipitation across mainland China in the period 2001-2010 from TRMM3B43 product using spatial downscaling approach. Remote Sens. 2015, 7, 5849-5878.

27. Shi, Y.; Song, L. Spatial downscaling of monthly TRMM precipitation based on EVI and other geospatial variables over the Tibetan Plateau From 2001 to 2012. Mt. Res. Dev. 2015, 35, 180-194.

28. Jing, W.; Yang, Y.; Yue, X.; Zhao, X. A Spatial Downscaling Algorithm for Satellite-Based Precipitation over the Tibetan Plateau Based on NDVI, DEM, and Land Surface Temperature. Remote Sens. 2016, 8, 655.

29. Almazroui, M. Calibration of TRMM rainfall climatology over Saudi Arabia during 1998-2009. Atmos. Res. 2011, 99, 400-414.

30. Condom, T.; Rau, P.; Espinoza, J.C. Correction of TRMM 3B43 monthly precipitation data over the mountainous areas of Peru during the period 1998-2007. Hydrol. Process. 2011, 25, 1924-1933.

31. Álvarez-Villa, O.D.; Vélez, J.I.; Poveda, G. Improved long-term mean annual rainfall fields for Colombia. Int. J. Climatol. 2011, 31, 2194-2212.

32. Manz, B.; Buytaert, W.; Zulkafli, Z.; Lavado, W.; Willems, B.; Robles, L.A.; Rodríguez-Sánchez, J.P. High-resolution satellite-gauge merged precipitation climatologies of the Tropical Andes. J. Geophys. Res. Atmos. 2016, doi:10.1002/2015JD023788.

33. Morán-Tejeda, E.; Bazo, J.; López-Moreno, J.I.; Aguilar, E.; Azorín-Molina, C.; Sanchez-Lorenzo, A.; Martínez, R.; Nieto, J.J.; Mejía, R.; Martín-Hernández, N.; et al. Climate trends and variability in Ecuador (1966-2011). Int. J. Climatol. 2016, doi:10.1002/joc.4597.

34. Huffman, G.J.; Bolvin, D.T.; Nelkin, E.J.; Wolff, D.B.; Adler, R.F.; Gu, G.; Hong, Y.; Bowman, K.P.; Stocker, E.F. The TRMM multisatellite precipitation analysis (TMPA): Quasi-global, multiyear, combined-sensor precipitation estimates at fine scales. J. Hydrometeorol. 2007, 8, 38-55.

35. Platnick, S.; King, M.D.; Ackerman, S.A.; Menzel, W.P.; Baum, B.A.; Riédi, J.C.; Frey, R.A. The MODIS cloud products: Algorithms and examples from Terra. IEEE Trans. Geosci. Remote Sens. 2003, 41, 459-473.

36. Solano, R.; Didan, K.; Jacobson, A.; Huete, A. MODIS vegetation index user's guide (MOD13 series). In Vegetation Index and Phenology Lab; The University of Arizona: Tucson, AZ, USA, 2010; pp. 1-38.

37. Hengl, T.; Heuvelink, G.B.; Rossiter, D.G. About regression-kriging: From equations to case studies. Comput. Geosci. 2007, 33, 1301-1315.

38. Krishnamurti, T.; Kumar, V. Improved seasonal precipitation forecasts for the Asian monsoon using 16 atmosphere-Ocean coupled models. Part II: Anomaly. J. Clim. 2012, 25, 65-88. 
39. Kumar, V.; Krishnamurti, T. Improved seasonal precipitation forecasts for the Asian monsoon using 16 atmosphere-Ocean coupled models. Part I: Climatology. J. Clim. 2012, 25, 39-64.

40. Zulkafli, Z.; Buytaert, W.; Onof, C.; Manz, B.; Tarnavsky, E.; Lavado, W.; Guyot, J.L. A comparative performance analysis of TRMM 3B42 (TMPA) versions 6 and 7 for hydrological applications over Andean-Amazon river basins. J. Hydrometeorol. 2014, 15, 581-592.

(C) 2017 by the authors. Licensee MDPI, Basel, Switzerland. This article is an open access article distributed under the terms and conditions of the Creative Commons Attribution (CC BY) license (http:/ / creativecommons.org/licenses/by/4.0/). 